\title{
LICITAÇÃO - PERMISSÃO DE USO - ATIVIDADE SIMILAR
}

- Mandado de Segurança. Edital de Licitação. Exploração de lanchonete. Permissão de uso. Outorga para atividade similar, alterando a destinação originária. Prejuizo ao impetrante. Recurso provido. Segurança concedida. Maioria de votos.

- Sendo incontroverso que as dependências ocupadas pelo vencedor destinavam-se às atividades de lanchonete, reservando-se as demais salas para atividades diferentes, a outorga de permissão a outrem para o ramo 
de mini-lanchonete e pastelaria - alterando a destinação - redundou em evidente prejuizo, que importou em violação a direito líquido e certo do impetrante.

\title{
SUPERIOR TRIBUNAL DE JUSTIÇA \\ Recurso Especial n² 147.666
}

\author{
Recorrente: José Geraldo Teixeira \\ Recorrido: Superintendência de Transportes e Terminais de Goiás - SUTEG \\ Recorrido: Geralda Nogueira da Silva \\ Recorrido: Paulo Roberto Silva Barros \\ Relator $p /$ acórdão: Sr. Ministro HÉLIO MOSIMANN
}

\begin{abstract}
ACÓRDÃo
Vistos, relatados e discutidos estes autos, acordam os Ministros da Segunda Turma do Superior Tribunal de Justiça, na conformidade dos votos e das notas taquigráficas a seguir, por maioria, conhecer do recurso e dar-lhe parcial provimento, nos termos do voto do $\mathrm{Sr}$. Ministro Hélio Mosimann. Participaram do julgamento os Srs. Ministros Hélio Mosimann e Adhemar Maciel. Não participaram do julgamento os Srs. Ministros Aldir Passarinho Júnior e Peçanha Martins.

Brasília, 3 de setembro de 1998 (data do julgamento).

Ministro Ari Pargendler, Presidente

Ministro Hélio Mosimann, Relator p/ acórdão
\end{abstract}

\section{RELATÓRIO}

O EXM ${ }^{2}$ SR. MINISTRO ARI PARGENDLER (RELATOR):

A Superintendência de transportes e Terminais de Goiás-Suteg publicou edital de licitação com a finalidade de "oferecer ao público outorga de permissão de uso de Unidades Comerciais no Terminal Rodoviário de Passageiros da Cidade de Alexânia-Goiás" (FL. 09).

A teor do item 1.5, "As unidades comerciais oferecidas, com as suas especificaçōes e respectivas atividades, encontram-se definidas no anexo no 01 , o qual faz parte integrante deste Edital" (fl. 10).

Nesse anexo, consta que a sala $n^{2} 4$ seria destinada à atividade de "lanchonete" (fl. 23), reservando-se as demais salas para as atividades de "bijouterias, farmácia, barbearia, BCA revista, frutaria" (fl. 23).

José Geraldo Teixeira participou da licitação e obteve a permissāo de uso "da unidade comercial no 4 (lanchonete)" - fl. 24/26.

Faltando licitantes para a maioria das salas, a Superintendência de Transportes e Terminais de Goiás-Suteg alterou-lhes a destinação originária e, sem licitaçāo, outorgou o uso de duas delas para Paulo Roberto Silva Barros e para Geralda Nogueira da Silva explorarem, respectivamente, as atividades de "mini-lanchonete" (fl. 27) e "pastelaria" (fl. 30).

O fato, alegadamente, prejudicou os negócios de José Geraldo Teixeira, o qual, por isso, impetrou o presente mandado de segurança para que "sejam cassadas imediatamente as Portarias 377 e 378, da SUTEG, maculadas com vício da ilegalidade, restabelecendo, de plano, o direito do impetrante de explorar sozinho a atividade de lanchonete no TRP de Alexânia, GO, conforme fora ofertado no Edital de Licitação da Concorrência Pública" (fl. 06/07).

A MM. Juíza de Direito Dra Edmée Aguiar de Farias Pereira denegou a ordem, destacando-se na sentença o seguinte trecho: 
"Analisando o termo de permissão de uso de fls. 24/26 dos autos, firmados entre impetrante e a SUTEG, em nenhuma de suas cláusulas está prevista a exclusividade alegada. $O$ edital de licitação de fl. 09/23 também não garante a exclusividade das atividades objeto do certame licitatório. Portanto, não apresenta a impetrante direito individual, liquido e certo, o que lhe daria legitimação para a propositura do mandamus" (fl. 87).

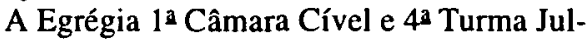
gadora do Tribunal de Justiça do Estado de Goiás, Relator o eminente Desembargador Matias W. de $O$. Negry, manteve a sentença (fl. 148/155).

Lê-se no julgado:

" $E$ inquestionável a ilegalidade dos contratos feitos pela SUTEG com os dois (02) particulares, uma vez que tais contratos foram feitos ao arrepio da Lei 8.666/93, sem qualquer licitação e sem qualquer ato de dispensa da mesma, essa ilegalidade é indiscutível. Ocorre que o apelante parte de uma premissa verdadeira (a ilegalidade) e chega a uma falsa conclusão qual seja: a exclusividade que pretende proferir-lhe o direito liquido e certo de explorar sozinho a atividade de lanchonete" (fl. 153/154). "Não vislumbro nos autos em nenhum momento, nem mesmo no Edital de Licitação essa garantia de exclusividade pretendida pelo ora apelante. Acredito que a SUTEG gerindo serviço público deve pautarse sempre pelo interesse coletivo ou melhor público" (fl. 15).

Seguiram-se embargos declaratórios (fl. 157/158), rejeitados (fl. 161/167), e daí o presente recurso especial, interposto com base no artigo 105, inciso III, letras " $a$ " e " $c$ ", da Constituição Federal, por violação do artigo 131 do Código Civil, do artigo 24, inciso V, da Lei $n^{2} 8.666$, de 1994 , do artigo $1^{\circ}$ da Lei $\mathrm{n}^{\mathrm{Q}} 1.533$, de 1951 , e do artigo $6^{\circ}$, $\$ 2^{\circ}$, da Lei de Introdução ao Código Civil (fl. 170/177).

Originariamente não admitida (fl. 189/192), o recurso especial foi processado por força de agravo de instrumento (fl. 194).

\section{VOTO}

O EXM ${ }^{\circ}$ SR. MINISTRO ARI PARGENDLER (RELATOR):
O artigo 131 do Código de Processo Civil foi observado pelo acórdāo recorrido.

"O juiz" - está dito nesse dispositivo "apreciará livremente a prova, atendendo aos fatos e circunstâncias constantes dos autos, ainda que năo alegados pelas partes; mas deverá indicar, na sentença, os motivos que lhe formaram o convencimento".

Pode ser que o julgado tenha interpretado mal o edital de licitação e o termo de permissão de uso que lhe seguiu, mas nele estāo articulados coerentemente os fundamentos da decisão.

Não há contradição entre reconhecer a ilegalidade da outorga das permissōes de uso outorgadas sem licitação e denegar a segurança à conta de que o Impetrante não tem o direito de explorar com exclusividade o ramo de "lanchonete" no terminal rodoviário.

São situaçōes distintas: a ilegalidade da outorga das permissões de uso tem como consequiência e respectiva anulaçāo, sem implicar o direito à exclusividade pretendida.

Essa exclusividade, se reconhecida, seria um direito individual, tutelado no âmbito do mandado de segurança (Lei nº 1.533, de 1951, art. $\left.1^{\mathbf{9}}\right)$. Já o direito de anular contrato não precedido de licitação é direito do cidadão, a ser exercido por ação popular (Lei $n^{\circledR} 4.717$, de 1965 , art. 40, III, “a”).

Nessa linha, e no contexto da causa, nāo há questão federal a ser examinada na via do recurso especial. Tanto a sentença de $1^{\mathcal{Q}}$ grau quanto o acórdão decidiram, à base do edital de licitaçāo e do termo de permissão de uso de fl. 24/26. O Superior Tribunal de Justiça não pode, no âmbito do recurso especial, reinterpretar esses textos.

Daí a conclusão de que o julgado foi prolatado também sem qualquer agravo ao artigo 24 , inciso $V$, da Lei $n^{2} 8.666$, de 1994 , ao artigo $1^{\circledR}$ da Lei $n^{2} 1.533$, de 1951 e ao artigo $6^{\circ}, \S 2^{2}$, da Lei de Introdução ao Código Civil.

Voto, por isso, no sentido de não conhecer do recurso especial.

\section{CERTIDĀO DE JULGAMENTO SEGUNDA TURMA}

№ Registro: 97/0063711-5 
RESP 00147666/GO

PAUTA: $19 / 03 / 1998$

JULGADO: $19 / 03 / 1998$

Relator: Exmo. Sr. Min. ARI PARGENDLER

Presidente da Sessāo: Exmo. Sr. Min. ARI PARGENDLER

Subprocurador-Geral da República: Exmo. Sr. Dr. MOACIR GUIMARĀES MORAIS FILHO

Secretário: Sra. Dra. BARDIA TUPY VIEIRA FONSECA

\section{AUTUAÇÃo}

Recte.: José Geraldo Teixeira

Advogado: João Moreira Santos e outros

Recado.: Superintendência de Transportes

e Terminais de Goiás-SUTEG

Advogado: Wilmar Dias da Silva e outros

Recado.: Geralda Nogueira da Silva

Advogado: Valdivino Clarindo Lima

Recado.: Paulo Roberto Silva Barros

Advogado: Cleima Jaime de Moraes Freitas

\section{SUSTENTAÇÃO ORAL}

Sustentaram oralmente os Drs. João Moreira Santos, pelo recorrente e Moacir Guimarães Morais Filho, Subprocurador-Geral da República.

\section{CERTIDÃO}

Certifico que a egrégia SEGUNDA TURMA ao apreciar o processo em epígrafe, em sessão realizada nesta data, proferiu a seguinte decisão:

“Após o voto do Sr. Ministro-Relator, não conhecendo do recurso, pediu vista dos autos o Sr. Ministro Hélio Mosimann. Aguardo o Sr. Ministro Adhemar Maciel."

Ausente, justificadamente, o Sr. Ministro Peçanha Martins.

O referido é verdade. Dou fé.

Brasília, 19 de março de 1998

Sra. Dra. Bardia Tupy Vieira Fonseca, secretária.
VOTO-VISTA (VENCEDOR)

O SR. MINISTRO HÉLIO MOSIMANN:

Extraio do relatório feito pelo Ministro Ari Pargendler (Relator), relembrando a fase inicial do julgamento, o seguinte resumo:

A Superintendência de Transportes e Terminais de Goiás-Suteg publicou edital de licitação com a finalidade de "oferecer ao público outorga de permissão de uso de Unidades Comerciais no Terminal Rodoviário de Passageiros da Cidade de Alexânia-Goiás".

A teor do item 1.5, "As unidades comerciais oferecidas, com as suas especificações $e$ respectivas atividades, encontram-se definidas no anexo $n^{0} 01$, o qual faz parte integrante deste Edital.

Nesse anexo, consta que a sala $n^{2} 4$ seria destinada à atividade de lanchonete, reservando-se as demais salas para atividades de bijouterias, farmácia, barbearia, banca de revista e frutaria.

José Geraldo Teixeira, o recorrente, participou da licitaf̧āo e obteve a permissão de uso da unidade comercial $n^{\varrho} 4$.

Faltando licitantes para a maioria das salas, a Superintendência alterou-lhes a destinação originária e, sem licitação, outorgou o uso de duas delas para Paulo Roberto Silva Barros e para Geralda Nogueira da Silva explorarem, respectivamente, as atividades de mini-lanchonete e pastelaria.

$O$ fato, segundo ale gação feita, prejudicou os negócios de José Geraldo Teixeira, que, por isso, impetrou o mandado de segurança para que "sejam cassados imediatamente as Portarias 377 e 378, da Suteg, maculadas com vício da ilegalidade, restabelecendo, de plano, o direito do impetrante de explorar sozinho a atividade de lanchonete no TRP de Alexânia, conforme fora ofertado no Edital de Licitação da Concorrência Pública".

Denegada a segurança, a Egrégia $1^{a}$ Câmara Cível do Tribunal de Justiça, manteve a sentença.

Seguiram-se embargos declaratórios, rejeitados, e dai o recurso especial, interposto com base no artigo 105, inciso III, letras " $a$ " $e$ "c", da Constituição Federal, por violação do artigo 131 do Código civil; do artigo 24, 
inciso V, da Lei $n^{2} 8.666 / 94$; do artigo Ió da

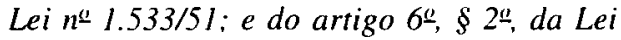
de Introdução ao Código Civil.

Pelo voto do eminente Relator, o especial não era de ser conhecido.

Assaltando-me algumas dúvidas, pedi vista dos autos.

Em síntese, o recorrente reclama prejuizo porque seu comércio veio a sofrer com a concorrência da atividade similar.

Não conheço também do recurso pela alí. nea "c" - dissidio jurisprudencial - pois não demonstrada a divergência. $O$ único acórdão trazido a confronto, desta mesma Turma, tratando da questão de forma genérica, não revela dissídio com a decisão recorrida.

Da mesma forma, sigo o Relator em relação à contrariedade aos artigos 131 do Código Civil, 24 da Lei 8.666/94 e 6 da Lei de Introdução ao Código Civil.

Minha discordância situa-se na aplicação do artigo $I^{\circ}$ da Lei $n^{2}$ 1.533/51. Se é incontroverso, segundo o chamamento do edital e seu anexo n⿳01-e isso nem comporta discussão - que a sala no 4, ocupada pelo impetrante e vencedor da licitação, destinou-se à atividade de lanchonete, reservando-se as demais salas para as atividades de bijouterias, farmácia, banca de revista e frutaria, $a$ outorga de permissāo a outrem para o ramo de mini-lanchonete e pastelaria, redundou em evidente prejuízo a quem já explorada regularmente e legalmente a mesma atividade.

Tal prejuizo, por sua vez, importou em violação a direito e direito líquido e certo do impetrante, qual seja, o de de explorar o ramo de lanchonete.

É claro que o vencedor só concorreu, habilitando-se na licitação, e esta só lhe interessa, nas condições ali estipuladas, quer dizer, desde que as outras salas se destinassem a atividades diferentes.

Mudada a regra do jogo, no meu modo de ver, caracteriza-se a violação ao artigo $l^{2}$, da Lei $n^{\circ}$ 1.533, de 1951.

Por isso é que conheço do recurso pela alinea " $a$ ", dando-lhe provimento parcial, nāo para anular inteiramente as duas Portarias mencionadas, mas para invalidá-las no tocante à destinação. Nada impede sejam as demais salas destinadas às atividades comerciais determinadas no edital.

É como voto, data vênia.

\section{CERTIDÃO DE JULGAMENTO SEGUNDA TURMA}

№ Registro: 97/0063711-5

RESP 147666/GO

Pauta: $19 / 03 / 1998$

Julgado: 16/04/1998

Relator: Exmo. Sr. Min. Ari Pargendler

Presidente da Sessão: Exmo. Sr. Min. Ari

Pargendler

Subprocurador-Geral da República: Exmo. Sr. Dr. Eduardo Antonio Dantas Nobre

Secretário: Sra. Dra. Bardia Tupy Vieira Fonseca

\section{AUTUAÇÃO}

Recte.: José Geraldo Teixeira

Advogado: João Moreira Santos e outros

Recdo.: Superintendência de Transportes e Terminais de Goiás-Suteg

Advogado: Wilmar Dias da Silva e outros

Recdo.: Geraldo Nogueira da Silva

Advogado: Valdivino Clarindo Lima

Recdo: Paulo Roberto Silva Barros

Advogado: Cleima Jaime de Moraes Freitas

\section{CERTIDÃO}

Certifico que a egrégia SEGUNDA TURMA ao apreciar o processo em epígrafe, em sessão realizada nesta data, proferiu a seguinte decisão:

"Prosseguindo no julgamento, após o votovista do Sr. Ministro Hélio Mosimann, conhecendo do recurso especial e lhe dando parcial provimento, pediu vista dos autos o Sr. Ministro Adhemar Maciel."

Ausente, justificadamente, o Sr. Ministro Peçanha Martins.

O referido é verdade. Dou fé.

Brasília, 16 de abril de 1998

Sra. Dra. Bardia Tupy Vieira Fonseca, secretária. 


\section{VOTO-VISTA}

O EXCELENTISSIMO SENHOR MINISTRO ADHEMAR MACIEL:

Senhor Presidente, pedi vista. V. Ex ${ }^{\mathbf{a}}$, como relator, não conheceu do recurso especial de JOSÉ GERALDO TEIXEIRA.

$O$ ora recorrente especial impetrou mandado de segurança contra ato do DIRETOR-GERAL DA SUPERINTENDÊNCIA DE TRANSPORTES E TERMINAIS DE GOIÁS (SUTEG). Alegou que a Suteg, em 05/08/93, abriu concorrência pública com o fim de selecionar interessados na exploração de unidades comerciais no Terminal Rodoviário de Alexânia. Pois bem, ele, impetrante, venceu a concorrência para a unidade $n^{2} 4$ (lanchonete). Em 10/03/94, foi firmado o contrato de permissāo entre o impetrante e a Suteg. Como não houve concorrentes em número suficiente para outras lojas, a Suteg baixou as Portarias ns $377 \mathrm{e} 378$, permitindo que outros interessados também explorassem o mesmo ramo do ora impetrante. Desse modo, Paulo Roberto Silva Barros e Geralda Nogueira da Silva passaram a explorar as atividades de minilanchonete e pastelaria, respectivamente, no Terminal de Alexânia. Ora, o impetrado não poderia ter agido em desconformidade com o que já fora, antes, assentado com o impetrante, tudo com base na Lei $\mathrm{n}^{\mathbf{2} 8.666 / 93}$. O edital só havia destinado uma sala, a de número 4 , para lanchonete. As outras eram para bijuterias, farmácia, barbearia, revista e frutaria. Com a exploração de ramos conexos, seu prejuízo aflorou sensivelmente.

Por último, o impetrante instou fossem cassadas as Portarias nºs 377 e 378 da Suteg, para que ele explorasse, sozinho, a atividade de lanchonete.

2. $O$ juiz indeferiu o pedido de liminar.

3. Os litisconsortes passivos se manifestaram, às fls. $49 / 50$ e 53 , porfiando pela sustenção do ato impugnado.

4. Em suas informações, o impetrado começou por dizer que ao impetrante faltava o direito líquido e certo. A seguir, disse que, de seis salas para exploração via permissāo administrativa, somente dois concorrentes dentre eles o impetrante - se habilitaram.
Verificou-se, assim. através do desinteresse de concorrentes, que outra política teria que ser adotada. É que em cidades pequenas, onde os terminais rodoviários são utilizados tão-somente como ponto de parada, diminutas são as outras atividades. Como a Suteg opera com receitas próprias, nāo se pode dar ao luxo de manter salas fechadas com o fim de afastamento de concorrentes de quem já explora determinado ramo. Ademais, cabe à Suteg, dentro da gama de sua discrição, alterar as destinações das unidades permitidas, tudo com o fim de melhor atender ao objetivo maior de sua existência.

5. O mandado de segurança foi denegado (fls. 83/88), ao fundamento de que o edital de licitaçāo nāo garantia a exclusividade das atividades.

6. O impetrante apelou.

7. O TJGO, tendo como relator o eminente Desembargador MATIAS NEGRY, conheceu do recurso ordinário, improvendo-o, todavia. A ementa do aresto ficou assim cristalizada:

“MANDADO DE SEGURANÇA. DIREITO LÍQUIDO E CERTO INCOMPROVADO. 1 - Se inexiste o direito líquido e certo que se busca proteger, por mandado de segurança declara-se a carência de ação. 2 - A ilegalidade existentes não induz a pretensão de exclusividade, e nem fere o direito líquido e certo. Apelo conhecido e improvido. Decisão confirmada."

8. Inconformado com o resultado, o impetrante interpôs recurso especial após ter interposto embargos declaratórios (rejeitados).

9. No recurso especial (alínes " $a$ " $e$ " $b$ "), o recorrente falou que, quando firmou o contrato de permissão, estava certo de que exploraria, sozinho, o ramo de lanchonete durante o período contratual de cinco anos. Foi por isso que investiu dinheiro no empreendimento. $\mathrm{O}$ ato impugnado violou o inciso $\mathrm{V}$ do art. 24 da Lei n. 8.666/94, que dispõe: "É dispensável a licitação.... V - quando não acudirem interessados à licitação anterior a esta, justificadamente, não puder ser repetida sem prejuízo para a administração, mantidas neste caso, todas as condiçōes pré-estabelecidas".

"A Suteg" - continuou o recorrente a argumentar - "modificou as finalidades das 
salas 3 e 6, que eram destinadas à exploração das atividades de bijuterias e barbearia, respectivamente, passando-as para mini-lanchonete e pastelaria, atividades comerciais estas a serem exploradas por seus beneficiários pelo prazo de um ano, em concorrência desleal com a atividade da permissão de uso do recorrente, que é destinada, no edital de concorrência pública, à exploração da atividade de lanchonete, prejudicando-o".

Por último, o recorrente repisou seu arrazoado, dizendo que o acórdão recorrido era nulo, uma vez que não estava fundamentado (CPC, art. 131). O ora recorrente, então impetrante, havia demonstrado à saciedade que o impetrado havia, ao arrepio da lei, alterado pelas Portarias nes 377 e 378 as condições anteriores fixados, trazendo prejuízo para ele, recorrente. Ferido restou o inciso $\mathrm{V}$ do art. 24 da Lei $n^{\mathrm{Q}} 8.666 / 93$, bem como o parágrafo $2^{\mathrm{Q}}$ do art. $6^{\circ}$ da Lei $n^{2} 4.657 / 42$ e $o$ art. $1^{\circ}$ da Lei $n^{0} 1.533 / 51$.

10. V. Exa ${ }^{2}$, Senhor Presidente, ao não conhecer do recurso, asseverou que, bem ou mal, a sentença estava fundamentada. Assim, não se podia falar em violação do 131 do CPC. "Não há contradição entre reconhecer a ilegalidade da outorga das permissões de uso outorgadas sem licitação e denegar a segurança à conta de que o Impetrante não tem o direito de explorar com exclusividade o ramo de lanchonete no terminal rodoviário. São situações distintas: a ilegalidade: a ilegalidade da outorga das permissōes de uso tem como consequiência a respectiva anulação, sem implicar o direito à exclusividade pretendida".

Por último, V. Ex asseverou que não havia, quanto as outras alegadas violações, infrigência a dispositivo federal. Tanto a sentença de primeiro grau quanto o acórdāo decidiram a questão à base do edital de licitação e do termo de permissão de uso.

11. O eminente Ministro MOSIMANN, em voto-vista, após um apanhado dos fatos processuais, também não conheceu do recurso pela alínea " $c$ ". "O único acórdāo trazido a confronto, desta mesma Turma, tratando da questão de forma genérica, não revela dissídio com a decisão recorrida". Também apoiou $V$.
Exa no tocante à alegada violação do art. 131 do CPC e do art. 24 da Lei $n^{2} 8.666 / 93$ e art. $6^{\circ} \mathrm{da}$ LICC.

O Ministro MOSIMANN, a seguir, arrematou:

“Minha discordância situa-se na aplicação do artigo $1^{2}$, da Lei $n^{\mathfrak{2}} 1.533 / 51$. Se é incontroverso, segundo o chamamento do edital e seu anexo $n^{2} 01-e$ isso nem comporta discussão - que a sala $n^{\circ} 4$, ocupada pelo impetrante e vencedor da licitação, destinou-se à atividade de lanchonete, reservando-se as demais salas para as atividades de bijouterias, farmácia, banca de revista e frutaria, a outorga de permissão a outrem para o ramo de mini-lanchonete e pastelaria, redundou em evidente prejuízo a quem já explorava regularmente, e legalmente a mesma atividade".

Se houve mudança de regra do jogo, caracterizada restou a violação do art. $1^{\mathbf{2}}$ da Lei $n^{\mathbf{2}}$ $1.533 / 51$. Daí ter o Ministro MOSIMANN conhecido e provido o recurso em parte, para que as atacadas portarias do impetrado fossem invalidadas somente no tocante à destinação.

12. Senhor Presidente, o eminente relator $a$ quo chegou à conclusão de que as duas últimas portarias do impetrado são nulas. São nulas porque contrariam a Lei $\mathrm{n}^{\mathbf{0}} \mathbf{8 . 6 6 6 / 9 3}$. Diz o eminente relator:

"É inquestionável a ilegalidade dos contratos feitos pela SUTEG com os dois (02) particulares, uma vez que tais contratos foram feitos ao arrepio da lei 8.666/93, sem qualquer licitação e sem qualquer ato de dispensa da mesma, essa ilegalidade (é) indiscutível".

Ora, Senhor Presidente, se as portarias que permitiram os litisconsortes contratarem com o serviço público são nulas por violação de lei federal, os referidos contratos não têm sustentação. Logo, o mandado de segurança teria que ser concedido em parte. $O$ impetrante é bom que fique bem claro - pede para anular as portarias e ficar sozinho na atividade de exploração de lanchonete.

Ninguém que conheça o mínimo de direito administrativo vai se abalançar a defender a tese de que o ora recorrente especial, então impetrante, terá o direito de impedir a permitente de mudar a destinação das salas. Estamos diante de contrato de permissão, que, por 
natureza. é precário. Mas a situaçāo fática. concreta, é bem outra. $O$ que o impetrado nāo poderia fazer, como bem ressaltou o Ministro MOSIMANN, era alterar as regras do jogo. Poderia, nos termos da lei federal então em vigor, baixar outro edital e, por exemplo, dizer que todas as seis salas seriam destinadas a lanchonetes etc. Tudo isso está na órbita de sua discricionariedade. Quem quisesse, então, que arriscasse, que enfrentasse a concorrência comercial, que ganhasse menos dinheiro. Mas, isso não foi feito $O$ que aconteceu? Por não haver licitantes, o impetrado fez contrato com novos interessados, mas, - aí é que está o pecadilho legal - sem publicar novo edital. Em decorrência, alterou-se o que, antes, dispunha o edital, que reservava apenas uma ala, a de número 4, para lanchonete. Assim, a mudança da regra editalícia foi feita, como acertadamente reconheceu o próprio acórdão recorrido, ao arrepio da lei, trazendo prejuízo para quem havia confiado na lisura da Administração pública. Quando o impetrante se habilitou, ganhou a concorrência e assinou o contrato, ele sabia que só haveria, nas condições daquele edital, uma sala destinada a lanchonete.

Os fatos estāo provados. Logo, satisfeita está a condição especial para o deslinde via mandado de segurança. No mérito, a segurança merecia ser concedida, ainda que em parte, como se falou mais de uma vez, pois o próprio relator a quo reconheceu a contraveniência das portarias à Lei $n^{2} 8.666 / 93$.

Cretella Jr., ao comentar o inciso V do art. 24 da Lei 8.666/93, observa:

"Aberta a licitação, pode ocorrer o caso de que não se inscreva nenhum interessado para concorrer ao certame. Nesta hipótese, é dispensável o procedimento licitatório, sempre que este, motivadamente, nāo puder ser renovado, sem prejuízo, para a Administração e, neste caso serão mantidas todas as condições anteriormente preestabelecidas, no edital, quanto a obras, serviços e compras" (Das licitações públicas, 14, ed. Rio de Janeiro: Forense, 1998, p. 2330).

E o impetrado, fazendo tábula rasa do inciso $\mathrm{V}$ do art. 24 da Lei $\mathrm{n}^{\mathrm{e}}$ 8.666/93, fez dois contratos novos, alterando a especificação do edital. Violou a lei, pois.
No tocante ao art. $1^{9} \mathrm{da}$ LMS, que trata do direito líquido e certo, peço vênia ao Ministro MOSIMANN para dele discordar. É que me filio à melhor doutrina, no meu entender, que vê no direito líquido e certo uma condiçāo especial da ação de mandado de segurança. Vale dizer, o direito líquido e certo nada tem a ver com o mérito. Diz respeito única e exclusivamente ao processo. Direito líquido e certo é prova provada com a inicial. É documento juntado, demonstrando o que se deduziu na petição inicial (Daí os autores alemāes falarem em Urkundenprozess - processo de documento).

Finalizando. Não conheço do recurso pela alínea "c". Como muito bem demonstrou o voto-vista do Ministro MOSIMANN, o dissídio jurisprudencial não está caracterizado.

Pela alínea " $a$ ", conheço do recurso, uma vez que ficou comprovada a contrariedade à Lei n. 8.666/93. Dou, dessarte, provimento ao recurso para anular as portarias nas quais se basearam os contratos dos litisconsortes. Em outras palavras, fica concedido, em parte, o mandado de segurança. Custas, pela recorrida.

\section{CERTIDÃO DE JULGAMENTO SEGUNDA TURMA}

№ Registro: 97/0063711-5

RESP 00147666/GO

PAUTA: $19 / 03 / 1998$

JULGADO: 03/09/1998

Relator: Exmo. Sr. Min. ARI PARGENDLER

Presidente da Sessão: Exmo. Sr. Min. ARI PARGENDLER

Subprocurdor-Geral da República: Exmo. Sr. Dr. WAGNER DE CASTRO MATHIAS NETTO

Secretária: Sra. Dra. BARDIA TUPY VIEIRA FONSECA

\section{AUTUAÇÃO}

Recte.: José Geraldo Teixeira

Advogado: João Moreira Santos e outros 
Recdo.: Superintendência de Transportes e Terminais de Goiás - Suteg

Advogado: Wilmar Dias da Silva e outros Recdo.: Geralda Nogueira da Silva Advogado: Valdivino Clarindo Lima Recdo.: Paulo Roberto Silva Barros Advogado: Cleima Jaime de Moraes Freitas

\section{CERTIDÃO}

Certifico que a egrégia SEGUNDA TURMA ao apreciar o processo em epígrafe, em sessão realizada nesta data, proferiu a seguinte decisão:
Prosseguindo-se no julgamento, após o voto-vista do Sr. Ministro Adhemar Maciel, vencido o Sr. Ministro-Relator, a Turma, por maioria, conheceu do recurso e deu-lhe parcial provimento, nos termos do voto do Sr. Ministro Hélio Mosimann que lavrara o acórdão.

Participaram do julgamento os Srs. Ministros Aldir Passarinho Júnior e Peçanha Martins.

O referido é verdade. Dou fé. Brasília, 3 de setembro de 1998.

Secretária: Sra. Dra. BARDIA TUPY VIEIRA FONSECA 